\title{
SUPERHYDROPHOBIC NATURE OF SOME PLANT LEAVES
}

\author{
M Gobalakrishnan \\ Assistant Professor level III, \\ Department of Textile Technology, \\ Bannari Amman Institute of Technology, \\ Sathyamangalam, Erode District, Tamil Nadu, \\ India.
}

\author{
S Anubama, S Aravindan, V Bharath \\ Student, Department of Textile Technology, \\ Bannari Amman Institute of Technology, \\ Sathyamangalam, Erode District
}

\begin{abstract}
The hydrophobic is water hating nature. Mostly, the hydrophobic structures are used in many places, like water repellent fabrics, water repellent finish and etc., in this, the water will not be absorbed. Whereas, the super hydroscopic properties even superior than the hydrophobic properties. It will not wet and it will form a ball like structure over the object. In this review, the leafs, Alocasia macrorrhizos, Alchemilla mollis, Nelumbo Nucifera, Colocasia esculenta, Rosa Rubiginosa, Salvina Molesta, which possess the superhydrophobic peroperties are explained.
\end{abstract}

Keywords - Superhydrophobic surfaces, lotus effect, leaf, wetting, hydrophobic, Alocasia macrorrhizos, Alchemilla mollis, Nelumbo Nucifera, Colocasia esculenta, Rosa Rubiginosa, Salvina Molesta

\section{INTRODUCTION}

Superhydrophobic surfaces are highly hydrophobic, they can't allow water to penetrate into their body. They are extremely difficult to wet. After analyzing superhydrophobic nature of lotus leaves, they are also referred as lotus effect (Mockenhaupt et al., 2008). The water droplets striking these kinds of leaf surfaces can fully rebound like an elastic ball. If the contact angle of such droplets exceed $150^{\circ}$ they are superhydrophobic in nature. Super-hydrophobic and hydrophobic surfaces have a potential specialized applications like, self-cleaning, low drag, antifouling, water reaping, hostile to icing and recently, superhydrophobic applications were designed on development of micro fuel cell chips, paper based electronics, medical industries (Hans J Ensikat et al., 2011). An astounding model is a lotus leaf, that shows nonwetting qualities because of the nearness of smaller scale and nanoscale includes on its surface. Specifically, they ascribed non-wetting qualities to microstructures and wax present on a superficial level (Nasri et al., 2014). In this review some plant materials that has the super-hydrophobic properties are explained.

\section{A. Superhydrophobicity of Alocasia macrorrhizos}

Alocasia macrorrhizos commonly called as Giant Taro, of family Araceae. Alocasia macrorrhiza is regularly utilized as a family unit embellishing plant (M. Kumar \& Bhardwaj, 2020). It is one of the tallest delicious herbaceous plant that can reach a height of $4.5 \mathrm{~m}$. It has an enormous prolonged stem, around $90 \mathrm{~cm}$ long and bolt formed leaves with shallow and adjusted lobes (Wagner et al., 2003). The leaves are strong, with sheathing in the lower part. The arrow shaped leafs are triangular in shape when it seen the overview of the leaf. There are around nine fundamental veins, separating at a point of around 60 degrees. The local spot of this plant is the rainforests from Borneo to Queensland. It is one of the staple harvests of Pacific Islands and it is plentifully developed there. It is an eatable plant, it has some needle like structures of calcium oxalate gems which are available in its sap. These needle like structures are called raphides it might cause skin bothering (science-conservation, n.d.). The plant has the calcium oxalate ingredients, which is very toxic (S. Khajja et al., 2011). The antioxidant properties of the plant makes the edible one and this is attributed by the extracts of diethyl ether (Mulla et al., 2010; Singh et al., 2010) . The antiinflammatory, anti-nociceptive and hepato-protective properties are also present in the ethanolic extracts of this plant. The antifungal properties of this plant is due to the presence of alocasin which is isolated from this plant (Wang $\& \mathrm{Ng}, 2003)$.

The leaf of Alocasia macrorrhizos has superhydrophobic properties and it is revealed in the Scanning Electron Microscopy (SEM) technique. The SEM image discovered that the outside of taro leaf has a wax film on its papillae (Mockenhaupt et al., 2008)(Joshi et al., 2015). It expands the contact edge of the leaf surface. This bio wax can be removed from the leaf surface by submerging taro leaves tests in 500 $\mathrm{mL}$ chloroform at $50^{\circ} \mathrm{C}$ for 30 seconds and the progression was rehashed for a similar example utilizing new chloroform. The dissolvable was dissipated utilizing rotational evaporator and the crude bio-wax arrangement was acquired. Hydrophobicity test indicated that the normal time for the test 
was 981 seconds which surpassed the 300 seconds constrained for hydrophilicity (M. Kumar \& Bhardwaj, 2020; Mockenhaupt et al., 2008; Nasri et al., 2014). The contact edge of Taro leaf is seen as $150^{\circ}$ which demonstrates the surface has superhydrophobic properties (Joshi et al., 2015; Wagner et al., 2003). The epidermal cells has a complex three dimensional microstructure which is there in surface of many plants. This epidermal cells are covered with a hydrophobic wax crystals. Because of this hydrophobic nature of the leaf, the water will not spread. On the other hand, it will form a spherical structure (Nasri et al., 2014)(Wagner et al., 2003).

\section{B. Superhydrophobicity of Alchemilla mollis}

Alchemilla mollis is commonly called as Lady's mantle of family Rosaceae. This herbaceous lasting plant is local to south parts of Europe and developed throughout the world as an elaborate nursery plant. It grows from $30 \mathrm{~cm}$ to $45 \mathrm{~cm}(12$ to 18 inches) tall, with leaves which are palmately veined, with a scalloeped and serrated edge (Makau, 2013; Trendafilova et al., 2012). The stipules are critical in which they are intertwined. It's a good old herbaceous perpetual that, other than being wonderful in gardens, is likewise utilized in making salves and cleansers. Woman's Mantle is an enduring perpetual blossom that is genuinely low-support and mixes well with other spring shorts. The foliage looks great all season and can make a decent ground spread under little trees (Küpeli Akkol et al., 2015). The plant is regularly developed as a groundspread, and it is esteemed for the presence of its leaves in humid climate. Water dots in the mornings on the leaves are because of their dewetting properties. These dots of water were considered by chemists to be the most flawless water. They utilized this water in their journey of transforming the raw metal into gold, hence the name comes Alchemilla (Shirtcliffe et al., 2011).

Accomplishing the 'Lotus Effect' predominantly depends on roughening the surface into numerous length sizes of unpleasantness with the goal that fluid beads can be held in the Cassie-Baxter state, where air pockets are caught under the fluid, decreasing the strong fluid interface (Blow \& Yeomans, 2010). This astounding water-repellent property is likewise found in other natural frameworks involving a majority of adaptable hairs or trichomes, and some of them have been perceived for more than 100 years. The expression "trichomes" for the most part alludes to outgrowths extending from little hairs to bigger outgrowths like thistles, it is regularly used to allude to the small hairs that can be seen rising up out of the surfaces of leaves and other epidermal surfaces of plants. On these trichomes the wax particles are available as rodlets which is liable for this superhydrophobic nature of this leaf surface. Fluffy leaves, for example, the Lady's Mantle, cause water drops to shape flawless circles and permit them to move off effectively because of being lifted and suspended by coming into contact with the hairs (Atul Mohandas Kootathil, 2016).

\section{Superhydrophobic nature of Nelumbo Nucifera}

Indian lotus (nelumbo nucifera) is also known as sacred lotus, bean of India, or Lotus. It is an extant species of an aquatic plant belongs to the family of nelumbonaceae. Lotus is also called as water lily (Hans J Ensikat et al., 2011). This species occurs in southern part of India and is mostly cultivated in the water garden. Lots of varieties are distributed worldwide, nearly 70 and 150 are accepted. The species nelumbo nucifera are not closely related to Lotus (Holloway, 1970; Rentschler, 1971). So the genus Lotus is currently undergoing extensive taxonomic research and is taxonomically complex. Lotus grows in water up to $2.5 \mathrm{~m}$ and its minimum water depth should not be less than $30 \mathrm{~cm}$. It requires nutrient rich loamy soil. It gets propagated either through seeds or buds. For its initial growth at first low level of water level is enough and after planting it requires high water level. Normally it takes three months for its complete growth, the flowers can be picked every two or three days. Seeds and its pods are harvested after four to eight months of planting. To separate the seed coats and embryos it kept for sun drying for about two to three days. They are traditionally harvested by hand using fork like tools but due to the Technology enhancement the labour are replaced with machines (NEINHUIS, 1997). Sacred lotus or India lotus is classified into three types according to their uses, Rhizome lotus, Seed lotus, Flower lotus. The flavonol miquelianin and alkaloids, coclaurine and naroclaurine are found in the leaves of lotus. The flower lotus is consumed as vegetables in many countries either it is sold as whole or cut into pieces, fresh, frozen, canned. Sometimes they are dried and used in soups or pickled in vinegar (Mockenhaupt et al., 2008). Lotus root is consumed as tea. It removes polluting compounds and metals during waste water treatment, has capacity to grow in different water conditions. It reduces the algae growth has high oxygen content $20 \%$ higher than the other aquatic areas (Wagner et al., 2003).

The lotus has self-cleaning properties as a result of ultrahydrophobicity. The dirt particles due to micro and endoscopic architecture are picked up by water droplets reduces the droplets adhesion to that surface. Other plants like cane, opubtia, tropaeolum also has ultrahydrophobicity and self-cleaning properties. As a result of contact of liquid with surface wetting may occur depending on the structure of the surface and fluid tension of the droplets. The epidemic part of the lotus have papillae of 10 to 20 micro meter in height and 10 to 15 micrometer in width so that the epicuticular waxes are imposed (H.J. Ensikat et al., 2006). Thus the superimposed waxes are hydrophobic. The hydrophobicity of any surface is measured by its contact angle. If the contact angle is higher, the hydrophobicity of surface is also higher. The surface whose contact angle is $<90^{\circ}$ is referred to as hydrophilic and with an angle $>90^{\circ}$ are referred to as hydrophobic and the plant with contact angle $160^{\circ}$ are called ultrahydrophobic (Hans J. Ensikat et al., 2009; Zhang et al., 2008). Superhydrophobic coatings are applied to microwave antennas and it reduces the rain fade. The superhydrophobic or 
hydrophobic properties are used in the dew harvesting or in the funneling of water to a basin for use in irrigation (Holloway, 1969). The groasis water boy with microscopic pyramidal structure depends on the ultrahydrophobic propriety that funnel condensation and rainwater into a basin for the release to a growing plants roots (Cheng et al., 2006; Zhang et al., 2009)

\section{Superhydrophobic Nature of Colocasia Esculenta}

Colocasia esculenta is a tropical plant originated form the kingdom plant of order alismatales and family araceae. The specific epithet esculenta means "edible" in Latin. This plant contains different names in different countries but it is generally called taro. It is an ornamental plant and often referred as "elephant ears" (Bhushan \& Jung, 2006; Harris et al., 1991). They contains rhizomes of different sizes and shapes. It is grown as root vegetable for its edible starchy corm. The size of these leaves are up to $40 \mathrm{~cm} \times 24.8 \mathrm{~cm}$. Which are sprout out from the rhizome. The dorsal part of the leaves are dark green in colour and the ventral part is light green. They are native to Southern India and Southeast Asia. It is highly polymorphic. It is cultivated largely in the Hawaiian Islands in Lower Hanalei valley. Taro can grow in paddy fields where water is abundant and grown in flooded areas. The Taro leaves are rich in vitamin A and C. The plant is toxic due to the presence of calcium oxalate when it is taken as raw form (Ferguson et al., 1992).

Colocasia esculenta leaves were collected from different areas and the samples carefully screened for any damages or dirt and they are washed with deionized running water and further blown with nitrogen on its surface. The contact angle of the droplets present on the leaf can be measured by placing a droplet on the prepared sample leaf using needle syringe and side view of the droplet was recorded and analyzed it in an image processing software (Burton \& Bhushan, 2006). The morphology of leaf surface was scanned with electron microscope. The measured advancing, receding and static angles of the leaf are $153^{\circ}, 144^{\circ}, 150^{\circ}$ respectively and it can be varying up to $2^{\circ}$. The contact angle was measured and the contact angle hysteresis was very small, to that of bio inspired surfaces of the leaf. The droplets stick to the bio inspired surface at an angle of $148^{\circ}$ (Harris et al., 1991). The Colocasia Esculenta leaves shows remarkable superhydrophobicity and water repellent properties. Yet bio inspired surface shows poor water repellent characteristics they can be employed to design devices for water harvesting due to their droplet sticking nature (Kaushal et al., 2012).

\section{E. Hydrophobicity of Rosa Rubiginosa}

Rosa Rubiginosa is commonly called as rose it belongs to the family Rosaceae, of the order Rosales. Rose, genus of some 100 species of perennial shrubs in the rose family (Rosaceae). Roses are mainly native to temperate northern hemisphere regions. Roses are erect, climbing, or trailing shrubs, the stems of which are usually copiously armed with pimples of various shapes and sizes, commonly referred to as thorns. The scale for rose flowers are often double (i.e., with multiple set of petals). The scale of rose flowers varies from tiny miniatures $1.25 \mathrm{~cm}$ (0.5inches) in diameter to hybrid flowers more than $17.5 \mathrm{~cm}$ (7inches) long. The fleshy, often edible, berry like fruit of the rose plant is known as trendy and typically varies in colour from red to orange (Moure et al., 2001). When you put a drop of water on a rose petal, it balls up but it doesn't fall off readily and the rose can be turned completely upside down when a small drop of water is on it and it will stick firmly to the petal. The Investigation was made by the team consists of many researchers by took a look at a rose petal under a scanning microscope and found that the petal have been riddled with microscopic bumps, around $16 \mu \mathrm{m}$ diameter and seven micrometers high. In turn each of these bumps were approximately $730 \mathrm{~nm}$ covered with folds. Such two characteristics have opposite effects on a droplet of water. Since the rose petal's chemical structure is initially somewhat hydrophobic, water can't get into the folds of the nanometer scale. That leads to a state of superhydrophobic. The authors have been able to construct a superhydrophobic surface in the present case, using a cast created by pouring polyvinyl alcohol on a rose petal and letting it dry. By drying into it a polystyrene chloroform solution they continued to create a new superhydrophobic material from the set (N. Kumar et al., 2018).

Rose petals have tiny outgrowths which are not apparent to the naked eye. Such outgrowths are called micro-papillae, give the petals ample roughness, with two fallouts. Another is that the petals are extremely water repellent, a property called superhydrophobicity, and two are rendered adhesively. The micro-papillae form seal with droplets of water which helps them to stick the petal surface. As per the research by the Chinese Academy of sciences, Jilin University, Changchun, and the National Center for Nanoscience and Technology, Beijing, the synthetic petals can be used as moulds for producing polymer films, paint coatings, usable fibres and microfluids (Moure et al., 2004).

\section{F. Hydrophobicity of Salvina Molesta}

Salvina molesta is also popularly known as the gaint salvina, it belongs to the family of Gallinacean of the order Salviniales. It is found between the regions of the Zimbabwe and Zambia. It has the excellent property of the hydrophobicity and doesn't attach to the soil. It stays still in the water by exhibiting the property of the hydrophobicity (Sharma \& Goel, 1986). Fronds of this plant are $0.5-4 \mathrm{~cm}$ long and broad, with a bristly surface caused by the hair-like strands that join at the end to form eggbeater shapes. Fronds are very much helpful in the waterproof covering of the plant, and they are usually produced in the pairs and it is most likely to the water fern it is hard to differentiate both of them. It is highly temperature dependent and it cannot grow in the salt water. The optimum 
temperature for the growth is 30 degree Celsius and the $\mathrm{pH}$ range should be between 6-7.7 (Sharma \& Goel, 1986). The uniqueness of this plant is, the capacity to retain dry air even when submerged in water (Hunt \& Bhushan, 2011). It also exhibits excellent buoyancy properties naturally and the plant is covered with the tiny hairs all over the surface (Tricinci et al., 2015). Every tip is designated to be hydrophilic so it has the property of the hydrophobicity and this hydrophilic hairs, helps to retain the air when the plant is submerged. It enables the trapping of the air between the small amount of the water they attract. Water molecules are always likely to be attached to the surface of the hairs thus reducing the instability in the environment (Balasubramanian et al., 2004; Yang et al., 2013).

\section{CONCLUSION}

Super hydrophobic structure is a structure which has the contact angle more than 150 degrees. Super hydrophobic is also called as ultra-hydrophobic. The microstrcutres present in the plant leaves has this properties. The plants Alocasia macrorrhizos, Alchemilla mollis, Nelumbo Nucifera, Colocasia esculenta, Rosa Rubiginosa, Salvina Molesta has excellent super hydrophobic structure. The microstructred wax present in these leaves, exhibits this property. These microstructres can be extracted and used to other object to improve the hydrophobicity of the object.

\section{REFERENCE}

[1]. Atul Mohandas Kootathil. (2016). Understanding The Alchemilla Leaf And Its Hydrophobicity (Issue May).

[2]. Balasubramanian, A. K., Miller, A. C., \& Rediniotis, O. K. (2004). Microstructured Hydrophobic Skin For Hydrodynamic Drag Reduction. Aiaa Journal, 42(2), 411-414. Https://Doi.Org/10.2514/1.9104

[3]. Bhushan, B., \& Jung, Y. C. (2006). Micro- And Nanoscale Characterization Of Hydrophobic And Hydrophilic Leaf Surfaces. Nanotechnology, 17(11), 2758-2772. 4484/17/11/008

[4]. Blow, M. L., \& Yeomans, J. M. (2010). Superhydrophobicity On Hairy Surfaces. Langmuir, 26(20), 16071-16083. Https://Doi.Org/10.1021/La101847b

[5]. Burton, Z., \& Bhushan, B. (2006). Surface Characterization And Adhesion And Friction Properties Of Hydrophobic Leaf Surfaces. Ultramicroscopy, 106(8-9), 709-719. Https://Doi.Org/10.1016/J.Ultramic.2005.10.007

[6]. Cheng, Y. T., Rodak, D. E., Wong, C. A., \& Hayden, C. A. (2006). Effects Of Micro- And Nano-Structures On
The Self-Cleaning Behaviour Of Lotus Leaves. Nanotechnology, 17(5), 1359-1362. Https://Doi.Org/10.1088/0957-4484/17/5/032

[7]. Ensikat, H. J., Boese, M., Mader, W., Barthlott, W., \& Koch, K. (2006). Crystallinity Of Plant Epicuticular Waxes: Electron And X-Ray Diffraction Studies. Chemistry And Physics Of Lipids, 144(1), 45-59. Https://Doi.Org/10.1016/J.Chemphyslip.2006.06.016

[8]. Ensikat, H. J., Ditsche-Kuru, P., Neinhuis, C., \& Barthlott, W. (2011). Superhydrophobicity In Perfection: The Outstanding Properties Of The Lotus Leaf. Beilstein Journal Of Nanotechnology, 2, 152-161. Https://Doi.Org/10.3762/Bjnano.2.19

[9]. Ensikat, H. J., Schulte, A. J., Koch, K., \& Barthlott, W. (2009). Droplets On Superhydrophobic Surfaces: Visualization Of The Contact Area By Cryo-Scanning Electron Microscopy. Langmuir, 25(22), 13077-13083. Https://Doi.Org/10.1021/La9017536

[10]. Ferguson, L. R., Roberton, A. M., Mckenzie, R. J., Watson, M. E., \& Harris, P. J. (1992). Adsorption Of A Hydrophobic Mutagen To Dietary Fiber From Taro ( Colocasia Esculenta), An Important Food Plant Of The South Pacific. Nutrition And Cancer, 17(1), 85-95. Https://Doi.Org/10.1080/01635589209514175

[11]. Harris, P. J., Ferguson, L. R., Roberton, A. M., Mckenzie, R. J., \& White, J. B. (1991). Cell-Wall Histochemistry And Anatomy Of Taro (Colocasia Esculenta). Australian Journal Of Botany, 39(3), 207222. Https://Doi.Org/10.1071/Bt9910207

[12]. Holloway, P. J. (1969). Chemistry Of Leaf Waxes In Relation To Wetting. Journal Of The Science Of Food And Agriculture, 20(2), 124-128. Https://Doi.Org/10.1002/Jsfa.2740200214

[13]. Holloway, P. J. (1970). Surface Factors Affecting The Wetting Of Leaves. Pesticide Science, 1(4), 156-163. Https://Doi.Org/10.1002/Ps.2780010411

[14]. Hunt, J., \& Bhushan, B. (2011). Nanoscale Biomimetics Studies Of Salvinia Molesta For Micropattern Fabrication. Journal Of Colloid And Interface Science, 363(1), 187-192. Https://Doi.Org/10.1016/J.Jcis.2011.06.084

[15]. Joshi, A., Karnawat, B. S., Narayan, J. P., \& Sharma, V. (2015). Alocasia Macrorrhiza: A Decorative But Dangerous $\quad$ Plant. 3(1), 221-223. Https://Doi.Org/10.17354/Ijss/2015/193

[16]. Kaushal, P., Kumar, V., \& Sharma, H. K. (2012). Comparative Study Of Physicochemical, Functional, Antinutritional And Pasting Properties Of Taro (Colocasia Esculenta), Rice (Oryza Sativa) Flour, Pigeonpea (Cajanus Cajan) Flour And Their Blends. Lwt 
- Food Science And Technology, 48(1), 59-68. Https://Doi.Org/10.1016/J.Lwt.2012.02.028

[17]. Kumar, M., \& Bhardwaj, R. (2020). Wetting Characteristics Of Colocasia Esculenta (Taro) Leaf And A Bioinspired Surface Thereof. Scientific Reports, 10(1), 1-15. Https://Doi.Org/10.1038/S41598-020-57410-2

[18]. Kumar, N., Kulsoom, M., Shukla, V., Kumar, D., Priyanka, Kumar, S., Tiwari, J., \& Dwivedi, N. (2018). Profiling Of Heavy Metal And Pesticide Residues In Medicinal Plants. Environmental Science And Pollution Research, 25(29), 29505-29510. Https://Doi.Org/10.1007/S11356-018-2993-Z

[19]. Küpeli Akkol, E., Demirel, M. A., Bahadır Acıkara, O., Süntar, I., Ergene, B., Ilhan, M., Ozbilgin, S., Saltan, G., Keleş, H., \& Tekin, M. (2015). Phytochemical Analyses And Effects Of Alchemilla Mollis (Buser) Rothm. And Alchemilla Persica Rothm. In Rat Endometriosis Model. Archives Of Gynecology And Obstetrics, 292(3), 619628. Https://Doi.Org/10.1007/S00404-015-3665-6

[20]. Makau, J. (2013). Anti-Influenza Activity Of Alchemilla Mollis Extract: Possible Virucidal Activity Against Influenza Virus Particles. Drug Discoveries \& Therapeutics.

Https://Doi.Org/10.5582/Ddt.2013.V7.5.189

[21]. Mockenhaupt, B., Ensikat, H. J., Spaeth, M., \& Barthlott, W. (2008). Superhydrophobicity Of Biological And Technical Surfaces Under Moisture Condensation: Stability In Relation To Surface Structure. Langmuir, 24(23),

13591-13597.

Https://Doi.Org/10.1021/La802351h

[22]. Moure, A., Dourado, F., Sineiro, J., Gama, F. M., \& Domínguez, H. (2004). Physicochemical, Functional And Structural Characterization Of Fibre From Defattedrosa Rubiginosa Andgevuina Avellana Seeds. Journal Of The Science Of Food And Agriculture, 84(14), 1951-1959. Https://Doi.Org/10.1002/Jsfa.1902

[23]. Moure, A., Sineiro, J., \& Domínguez, H. (2001). Extraction And Functionality Of MembraneConcentrated Protein From Defatted Rosa Rubiginosa Seeds. Food Chemistry, 74(3), 327-339. Https://Doi.Org/10.1016/S0308-8146(01)00185-6

[24]. Mulla, W. A., Kuchekar, S. B., Thorat, V. S., Chopade, A. R., \& Kuchekar, B. S. (2010). Antioxidant, Antinociceptive Anti-Inflammatory Activities Of Ethanolic Extract of Leaves Of Alocasia Indica (Schott.). Journal Of Young Pharmacists, 2(2), 137-143. Https://Doi.Org/10.4103/0975-1483.63152

[25]. Nasri, N. S., Ahmed, M. M., Mohd Noor, N., Mohammed, J., Hamza, U. D., \& Mohd Zain, H. (2014). Hydrophobicity Characterization Of Bio-Wax Derived
From Taro Leaf For Surface Coating Applications. Advanced Materials Research, 1043(October), 184-188. Https://Doi.Org/10.4028/Www.Scientific.Net/Amr.1043. 184

[26]. Neinhuis, C. (1997). Characterization And Distribution Of Water-Repellent, Self-Cleaning Plant Surfaces. Annals Of Botany, 79(6), 667-677. Https://Doi.Org/10.1006/Anbo.1997.0400

[27]. Rentschler, I. (1971). Die Wasserbenetzbarkeit Von Blattoberfl? Chen Und Ihre Submikroskopische Wachsstruktur. Planta, 96(2), 119-135. Https://Doi.Org/10.1007/Bf00386362

[28]. S. Khajja, B., Sharma, M., \& Singh, R. (2011). Forensic Study Of Indian Toxicological Plants As Botanical Weapon (Bw): A Review. Journal Of Environmental \& Analytical Toxicology, 01(02). Https://Doi.Org/10.4172/2161-0525.1000112

[29]. Science-Conservation. (N.D.). Alocasia Macrorrhizos. Source: Http://Www.Kew.Org/ScienceConservation/Plants-Fungi/Alocasia-MacrorrhizosElephant-Ear-Taro

[30]. Sharma, K. P., \& Goel, P. K. (1986). Studies On Decomposition Of Two Species Of Salvina. Hydrobiologia, 131(1), 57-61. Https://Doi.Org/10.1007/Bf00008324

[31]. Shirtcliffe, N. J., Mchale, G., \& I. Newton, M. (2011). The Superhydrophobicity Of Polymer Surfaces: Recent Developments. Journal of Polymer Science Part B: Polymer Physics, 49(17), 1203-1217. Https://Doi.Org/10.1002/Polb.22286

[32]. Singh, I., Mandal, P., \& Misra, T. (2010). Antioxidant Activity In The Extracts Of Two Edible Aroids. Indian Journal of Pharmaceutical Sciences, 72(1), 105. Https://Doi.Org/10.4103/0250-474x.62242

[33]. Trendafilova, A., Todorova, M., Gavrilova, A., \& Vitkova, A. (2012). Flavonoid Glycosides From Bulgarian Endemic Alchemilla Achtarowii Pawl. Biochemical Systematics And Ecology, 43, 156-158. Https://Doi.Org/10.1016/J.Bse.2012.03.013

[34]. Tricinci, O., Terencio, T., Mazzolai, B., Pugno, N. M., Greco, F., \& Mattoli, V. (2015). 3d Micropatterned Surface Inspired By Salvinia Molesta Via Direct Laser Lithography. Acs Applied Materials \& Interfaces, 7(46), 25560-25567. Https://Doi.Org/10.1021/Acsami.5b07722

[35]. Wagner, P., Fürstner, R., Barthlott, W., \& Neinhuis, C. (2003). Quantitative Assessment To The Structural Basis Of Water Repellency In Natural And Technical Surfaces. Journal Of Experimental Botany, 54(385), 1295-1303. Https://Doi.Org/10.1093/Jxb/Erg127 
[36]. Wang, H. ., \& Ng, T. . (2003). Alocasin, An Anti-Fungal Protein From Rhizomes Of The Giant Taro Alocasia Macrorrhiza. Protein Expression And Purification, 28(1), 9-14. Https://Doi.Org/10.1016/S10465928(02)00604-6

[37]. Yang, C.-Y., Yang, C.-Y., \& Sung, C.-K. (2013). Enhancing Air Retention By Biomimicking Salvinia Molesta Structures. Japanese Journal Of Applied Physics, 52(6s), 06gf08. Https://Doi.Org/10.7567/Jjap.52.06gf08

[38]. Zhang, J., Sheng, X., \& Jiang, L. (2009). The Dewetting Properties Of Lotus Leaves. Langmuir, 25(3), 13711376. Https://Doi.Org/10.1021/La8024233

[39]. Zhang, J., Wang, J., Zhao, Y., Xu, L., Gao, X., Zheng, Y., \& Jiang, L. (2008). How Does The Leaf Margin Make The Lotus Surface Dry As The Lotus Leaf Floats On Water? Soft Matter, 4(11), 2232. Https://Doi.Org/10.1039/B807857b 